\title{
A Contextual Integration of Individual and Organizational Learning Perspectives as Part of IS Analysis
}

\author{
Peter M. Bednar \\ School of Computing and Management Sciences, Sheffield Hallam University \\ Department of Informatics, Lund University
}

p.bednar@shu.ac.uk

\begin{abstract}
The Strategic Systemic Thinking (SST) framework is presented as a stepping stone towards enabling the refocusing of organizational analysis in Information Systems (IS). The paper introduces some of the fundamental assumptions regarding the objectives of the SST framework; such as sense making as learning processes build upon communicative actions. The main concepts of the SST framework are presented, which are focused on developing a learning organization inclusive of having a constructive dialogue mechanism. The SST framework includes constructive dialogue as a means of gaining access to the existing but unreleased individual and group competencies for improved IS analysis.
\end{abstract}

Keywords: Information systems, organizational analysis, organizational learning, sense making.

\section{Introduction}

Most everyone in the information systems field would agree that systems development work typically requires an analysis of existing organizational practices and procedures (Checkland, 1981; Avison \& Fitzgerald, 1988). This is the case because any new implementation or change to an existing information system can have a significant impact on the organization (Checkland \& Holwell, 1998). The importance of studying organizational change, as a result of information systems development, was recognized back in the 1960's. Early work identified the significance of the individual in the organizational infrastructure. This work was described in the "Theoretical Analysis of Information Systems" where the infological equation was presented (Langefors, 1995).

"The infological equation (Langefors, 1966): " $I=i(D, S, t)$ ": where I is the information (or knowledge) produced from the

Material published as part of this journal, either on-line or in print, is copyrighted by the publisher of Informing Science. Permission to make digital or paper copy of part or all of these works for personal or classroom use is granted without fee provided that the copies are not made or distributed for profit or commercial advantage AND that copies 1) bear this notice in full and 2) give the full citation on the first page. It is permissible to abstract these works so long as credit is given. To copy in all other cases or to republish or to post on a server or to redistribute to lists requires specific permission and payment of a fee. Contact Editor@inform.nu to request redistribution permission. data $D$ and the pre-knowledge $S$, by the interpretation process $i$, during the time t.[ ...] In the general case, $S$ in the equation is the result of the total life experience of the individual. It is obvious, from this, that not every individual will receive the intended information from even simple data." (Langefors, 1995, p.144).

The infological equation suggests that information systems include complex, intra-individual and inter-individual dimensions. With the inclusion of personal pre-knowledge, some of the ground work was laid (see Langefors, 1966), for what today is called soft systems development or social informatics. The infological equation includes the suggestion that individuals and their sense-making activities are to be included in the information system, (Langefors, 1995).

Although there is a wealth of literature on both organizational change (Child, 1984; Cash et al, 1994; Daft, 1998; Groth, 1999) and information systems development (Checkland, 1981; Avison \& Fitzgerald, 1988; Yourdon, 1989; Alter, 1996), the focus has been on the organization as a whole. Though we have recognized the individual's contribution in the organization, there has been little research done on the individual perspective of learning especially within the context of information systems (IS) development.

Much of the current research in IS has focused primarily on various aspects of structured learning in an organization 
(Senge, 1990; Agre \& Shuler, 1997; Travica, 1999; Eriksen, 1998; Zack; 1999). This can be exemplified by Senge's popular statement on organizational learning (1990, p. 69):

"I call systems thinking the fifth discipline because it is the conceptual cornerstone that underlies all of the five learning disciples of this book. All are concerned with a shift of mind from seeing parts to seeing wholes, from seeing people as helpless reactors to seeing them as active participants in shaping their reality, from reacting to the present to creating the future. Without systems thinking, there is neither the incentive nor the means to integrate the learning disciplines once they come into practice. As the fifth discipline systems thinking is the cornerstone of how learning organizations think about their world."

This description stresses systems thinking and integration within learning disciplines. However, it doesn't address an individual perspective in terms of reflective personal learning processes. The composition of these low-level processes may have a major impact on the organization (and information system) as a whole. It is argued in this paper that organizations, from an individual perspective, would benefit from a more formalised cross-fertilisation between ideas of organizational analysis and learning. What is needed is a systemic process for personal learning that is based on contextually dependent systems thinking.

Contextuality has to do with what Langefors (1966) describes as individual pre-knowledge as a result of the total life experience at a given point in time. This time-dependency as a part of learning is important since the understanding of a certain situation is dependent on the total life experience. Contextuality includes the impact of changes in the personal sensemaking processes due to changes in the personal understanding of life experience.

In the theory of autopoiesis, the objective of a system is described as an effort to uphold individual forms of identity (Maturana \& Varela, 1980). As such, as a systemic entity's understanding of itself changes, the system's sense making and understanding of the environment also changes. Contextual dependency is an effort to describe an ever changing understanding which is dependent upon a continual co-play among an "observer", "observation" and the "referential framework" (Maturana \& Varela, 1980). The "referential framework" can be viewed as the personal understanding of the "total life experience" at a given point in time (Langefors, 1966).

\section{Organizational Analysis}

Organizational analysis can be defined as a composition of both individual and organizational learning processes (Senge, 1990; Walsham, 1993; Argyris \& Schön, 1996). In this sense, the organization is constantly changing as individuals continually change their perception of the organization through learning processes. As a result, individual and organization learning cannot be separated as independent entities because they are intertwined.

What is needed is a study of learning mechanisms that support individual analysis activities (Senge, 1990; Argyris \& Schön, 1996). An important area of study associated with individual analysis is the sense making process, which is built upon communication and learning (Weick, 1995). The sense making process is an individual activity of "figuring out" or "problem-solving" within the context of the organization, its goals, and its strategies. The individual's sense making is also dependent on the organizational culture as a whole.

One of the problems with today's organizations is that individual sense making in the form of lessons learned are not shared within the organization. There are several explanations as to why lessons learned are taken for granted but not practised. According to Argyris (1990), one of the explanations has to do with "skilled incompetence". This is the case when managerial and professional behaviour creates habits of selfdenial, which inhibit certain kinds of progress within organizations.

Irrational decision-making can be attributed to the experience of overwhelming uncertainty connected to existing sense making activities. When viewed in this way, irrational decision-making becomes a "rational" or explained activity (Sjöstrand, 1997). With this in mind, questionable decisions cannot be universally blamed on a lack of individual competence within an organization. This is an example of the complexities and controversies that impact the facilitation of organizational learning. Argyris (1990) describes these roadblocks as "organizational defense" mechanisms. Other related controversies have to do with "organizational sense making" activities and the "Janus Factor" of rational decision-making (refer to Weick (1995) and Sjöstrand (1997); respectively, for an in-depth discussion of these organizational impediments to learning).

There are examples of industrial projects that failed even though existing competencies should have been enough and, if those same competencies had been employed, might have prevented the failures from occurring. There seems to be a consensus that organizational barriers to success are associated with learning styles, individual autonomy, and 
contextual-dependency but are relatively easy to overcome. There are suggested strategies on how to prevent these types of organizational failures (Handy, 1994; Senge, 1990), though there is still much work to be done. It is proposed in this paper that there are individual learning processes that will help ideas to surface. This is accomplished through an enrichment and visualization process for individual (and team-based) decision-making.

The objective of this work is to provide a proposal for an initial strategic systemic framework, which could be used instead of (or to challenge) the use of more traditional approaches to IS analysis. By using this framework, individual and organizational learning perspectives can be integrated in the IS analysis process.

\section{Learning Organization}

The concept of the learning organization, as presented by Argyris and Schön $(1978 ; 1996)$, is defined as a means to reflect upon, and re-evaluate the knowledge that is created by individuals within the organizational context. The organization is changed as a result of this learning process. The learning process can be viewed as an ongoing sense making activity based on the collective knowledge of the individuals.

The objective of the proposed strategic systemic thinking (SST) framework is to incorporate adaptation and change as a sense making process. This would be accomplished via a collective reflection of decision -making activities in the learning environment. This approach is similar to (but not equal with) the systemic five "disciplines" applied in a learning organization (refer to Senge (1990) for an in-depth discussion of the five disciplines). It is also similar to an organizational facilitation for double loop learning (Argyris, 1990; Argyris \& Schön, 1996). Double loop learning includes a reflection of the learning process whereby an effort is made to try to break out from prejudices and assumptions that individuals might have from past organizational experiences.

It is not sufficient for an organization to focus only on lessons learned or improve current practices in order to have this level of a sense making, learning strategy. Such an approach is referred to as a "first-order change" (Bateson, 1972) or "lessons learned" strategy. The major issue associated with being a learning organization includes "second-order change", which requires changes in fundamental organizing principles and basic assumptions (Bateson, 1972). Neither intra-individual nor inter-individual relationships are seen upon as being static. Thus organizational structures are viewed as dynamic and temporary open systems.
Organizations, when viewed as multi-individual, interactive (open) subsystems, are quite complex, as each subsystem exists as a separate entity. These subsystems are composed off individuals with skills, experience, and knowledge that unfortunately may not be recognized or taken advantage of.

Hastings (1996, p. 127) provides a summary of this sentiment:

"If managers actually mean it when they say, 'people are our greatest asset', and 'in the future it's our knowledge that we will be selling' then there should be many around who are seriously concerned about the poor return and utilization level that they are achieving from this knowledge asset lying invisible and under-utilized in peoples heads. Maximizing the return on an organization's know-how investment will be the most significant source of competitive edge in the future."

\section{Constructive Dialogues}

According to Checkland \& Holwell (1998), organizational change and improvement could only be successful when the organizational actors (individuals) are engaged in that change. Without incorporating these individuals in the change process, it is probable that a management-imposed solution will fail. Individuals that are not involved typically lack the commitment necessary for successful decision-making (Brunsson \& Olsen, 1997). Too often, management is unaware of the opportunity of inside resources and as a result try to tell these individual what to do. In addition, the insider knowledge-base and sense making experience may not be viewed as an asset or is unknown by the organization.

An example of this phenomenon is illustrated as follows. If an individual walks on a beach and picks up a stone, the individual might see a generic rock with no special features or characteristics. But if the individual were a geology student, he or she might recognize different kinds of minerals in that piece of rock. That is to say, an individual can only see what he or she knows and what he or she perceives as interesting.

Thus it is not enough for management to use an interventional approach that focuses on situations without regard for the individuals involved. This is relying only on what management knows and not utilizing the knowledge of the inside resources. Yet, these resources are necessary for the long-term growth and stability of an organization.

When a problem arises, it is important to engage the actors in reflecting on their experience when problem-solving during similar situations. But it is also important to involve active intervention external to the individuals or group performing the problem-solving activity. That intervention would aim for broadening the problem-solving perspectives of the organizational members. 
An intervention by an external party (e.g., researcher, consultant, or management) is an enquiry into the beliefs of the actors and the interventee. This enquiry, via an intervention, would necessitate a dialogue and learning activity. The interventee would have to address issues that are in need of a more active involvement by the individual participants. All parties, inclusive of the interventee, would have increased responsibility in the problem-solving process. The actors, within the context of the problem situation, should carry out the enquiry. The interventee would have limited responsibility in terms of offering support and guidance for the ongoing enquiry. This is a stronger form of intervention and call for more external responsibility taking then the more "non-interventionistic" approach or "interaction" as suggested by Checkland \& Holwell (1998).

Support should also be provided for broadening the possibilities of interpreting the problem and understanding the possibility that it might be highly unstructured. The broadening activity component of such an intervention is a complex learning activity. It is believed that a broadening activity needs to be undertaken before any other approach to intervention is made. As a result, a constructive dialogue is essential among all participants inclusive of the actors and interventee to promote an effective learning process. A dialogue must be based on trust as a result of actors feeling empowered and safe, in their respective fields of professional expertise and responsibility.

\section{Background of the SST Objectives}

As many as $90 \%$ of IT (information and communication technology) projects fail to meet their goals due to a misalignment of goals and organizational activities (Clegg et al., 1996). This misalignment may be due to goal-setting activities or the processes associated with IT development or implementation activities. In either case, it is difficult to gain an understanding of what caused the failure. It may be just as difficult to understand the successful components of a project. Both failure and success factors are difficult to extract as part of the learning process without effective communication among the actors and interventees.

One recent example of project failure is provided in the article "Grasping the ERP nettle" (Anon, 2000). The article discussed $£ 500,000$ investment in an enterprise resource system (SAP R/3) for the UK -based telecommunication consultancy company called Touchbase. The authors claim that the implemented enterprise resource system was seen as providing extremely good support for core business processes such as accounting. However, the article reports that the sales force found the new system disturbingly unsupportive of their work and the sales force resorted to previous, partly paper-based, practices following the introduction of the system. As a result, Touchbase chose to solve the surfaced precarious inadequacy by adding a tailor-made smaller system designed to provide better support for the business sales process. The total implementation was presented in the article as, on the whole, a success story. Though one could attribute the lack of success of this project as a direct result of a lack of participation by the individuals with the knowledge and experience necessary to problem-solve.

One major issue regarding the success or failure of a project is that IS development tends to be isolated within the organization as a separate entity from other projects. Bednar and Wang (1994) discuss this whereby several partly parallel system development processes were investigated over a period of two years. One of the system development processes was interconnected with ISO 9000, another one was closely related to organizational strategy and TQM, and a third one was associated with organizational IS. Though they were all IS projects, they were more or less isolated from each other in terms of organizational analysis.

IS development is supposed to consider organizational issues but too often IS is looked upon as a subsystem external or separate from the rest of the organization. Bednar (1999) provides a way to resolve this disparate view of IS development by viewing the organization itself as an information system. By taking this view, IS becomes an inherent part of an organization including its actors, and its supporting processes, and not a separate entity that exists external to these components. All organizational actors are, in this perspective, interactive, social members of the IS.

\section{A Contextually-Dependent Possibility}

What is needed is an organizational perspective that integrates IS (analysis, development and evaluation) into the decisionmaking process associated with organizational change. This might require a greater awareness of the need for integration between "macro" and "micro" perspectives of organizational change. The macro perspective can be related to open system theory as follows:

"Open system theory influenced organization researchers to focus on a new set of within organization variables, and especially to move from an atomistic research focus on individuals as units of analysis to dyadic or other relational units of analysis in which communication relationships were a priority focus, and to more systems-level concerns, in which communication network analysis was often utilized" (Rogers \& Agarwala-Rogers, 1976, p. 116). 
The "micro" perspective is related to what Rogers \& Agarwala-Rogers (1976) describes as "an atomistic" research focus. This means that the main unit in the organizational analysis is the individual, not the work group or the communicational structure. The focus is on how the individual perceives the structure. The atomistic perspective "can only explain behavior as a product of individual-level independent variables" (Rogers \& Agarwala-Rogers, 1976, p.117). However the "micro" perspective is not fully equal to the atomistic one. The micro perspective includes an analysis of the interindividual sense making where the individual entity is also seen as an open subsystem. This kind of individual sense making process can be explained with the theory of autopoiesis in terms of a subsystem's efforts in understanding itself as an entity with relations to a "super-system" or surrounding "world" (Maturana \& Varela, 1980).

IS analysis and individual contexts are also about communicational contextual influences for systems and information system development. Thus, an information system can be viewed in terms of its continual construction and reconstruction whereby reflections over perceptions can be seen as an ongoing learning process (Walsham, 1993; Argyris \& Schön, 1996).

How could the needed changes in approaches to IS analysis be done? Through combining the knowledge- base underpinning the two diverse areas of micro and macro perspectives and integrating these approaches in one framework. The "micro" area might be based upon an individual learning perspective and cognition, which is sometimes represented in HCI (human computer interaction) as philosophical, psychological and management research. The "macro" perspective relates to IS strategy, organizational learning, organizational information systems and information systems methodology research.

The proposed SST framework integrates macro and micro aspects of organizational change. This framework aims to assist users in applying techniques such as brainstorming, rich pictures and conceptual models from Soft System Methodology (refer to Checkland, 1981; Checkland \& Scholes, 1990; for an in-depth discussion of this methodology) and mental constructs from NIMSAD (Jayaratna, 1994) into useful methods for organizational analysis. The SST framework, shown in Figure 1, has been developed to support viable approaches (e.g., brainstorming), while trying to adapt specific methods used within the scope of contextually dependent problems.

SST offers a means of structuring highly unstructured, uncertain situations typically found in systems analysis work (though not limited to these activities). The framework could

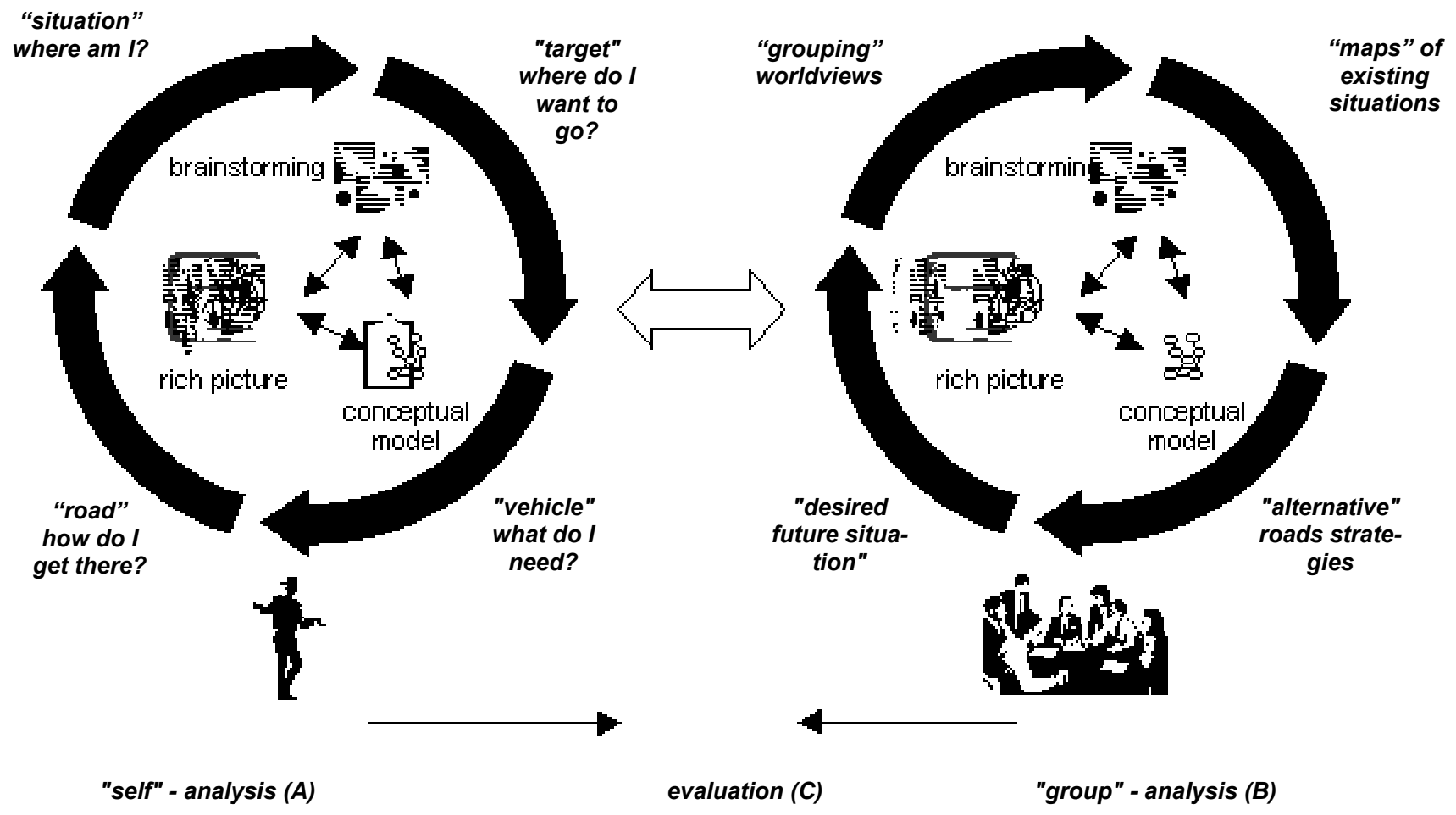

Figure 1: Overview of the SST framework. 
also be adapted to be used in conjunction with a specific approach currently being used in the organization. It is particularly useful when the problematic scope is highly uncertain and provides a basis for decision-making in this environment.

The contextual realities associated with sense making differ for each individual, based on an individual's understanding of the specific situation (e.g. contingency). The (intra-individual) relationships that might be reflected upon while trying to contextually transform the framework to a method, are not only related to experience and competence but also have to do with autonomy, initiative and risk taking. This is shown in Figure 2 .

To be able to take any kind of personal initiative, the individual has to feel professionally safe and have autonomy within the group. However, autonomy means differentiating individuals from others in the group. The existing culture has a strong influence on what kind of autonomy is acceptable (Ahrne, 1994). From an individual perspective there might be great insecurity associated with autonomy because of the organizational consequences. Initiatives that are not previously taken might have been dismissed without being presented because of notions of insecurity. Also there might exist experiences with earlier initiatives, which have failed in one way or another, and these negative experiences could have a prohibitive impact on proposing new ones. Initiatives, in this perspective, are clearly individual risk taking activities, which are dependent on the level of individual autonomy within the group. that innovations and creativity suffer. It is difficult for a risk taking individual to flourish in this environment, as there are few rewards and perhaps great penalties for doing so.

\section{A Framework for Strategic Systemic Thinking (SST)}

The components of the framework, shown in Figure 1, are for illustrative purposes. It is not intended that they have to be performed in a certain order. The organization would select the approaches that are appropriate for individuals and groups in order to create, use, and adapt contextually dependent methods. The framework should not be considered a questionnaire, which is to be answered by individuals in the organization. All questions are for illustrative purposes only. The systemic thinking itself should result in appropriate questions that are contextual in nature. A major impact is made by the so-called "timing loop" shown in the figure (e.g. all analysis are dependent on the contextual timing constraints). Contextual timing constraints are those constraints which individuals impose on themselves while deciding how much time they think is meaningful (and possible) to spend on a specific activity. For example, the time allotted to work on activity A may be re-evaluated by an individual when it is determined that more time is needed for activity $\mathrm{B}$.

Brainstorming, rich picture, mental constructs and conceptual models, as represented in Figure 1, can be viewed as vehicles for discussion by individuals and the team as a whole. They can also be considered learning exercises focused on evaluation and feedback in connection with the analysis work. They

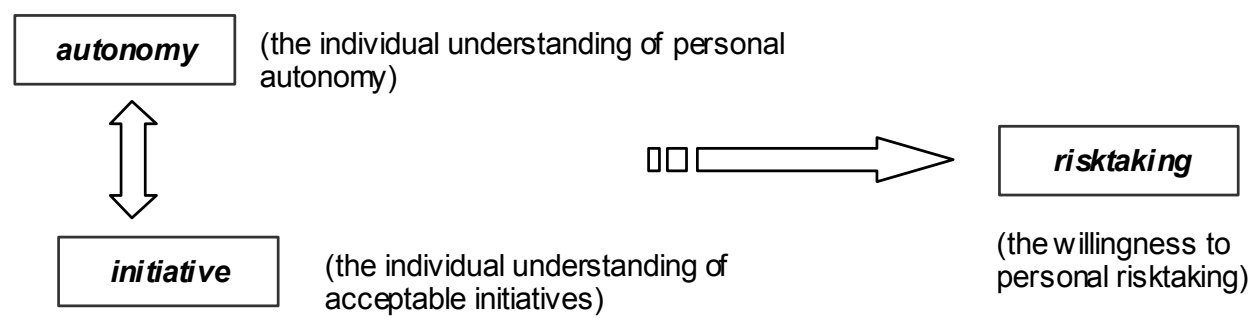

Figure 2: Relationships among understandings of autonomy and initiative as influences on risk taking activities.

Such individual risk taking activities and autonomy are mirrored in organizational cultures and prohibited or supported accordingly (Ahrne, 1994; Walsham, 1993). If the organizational climate does not support a high level of individual autonomy, the willingness to take the risk is minimized such can be used as constructive support activities for raising quality issues. Since the work is done both individually (analysis A e.g. intra-individually) and within the group (analysis B e.g. inter-individually), direct feedback is necessary to avoid adding work via miscommunication or redundancy of effort. 
Observation, group dynamics, drama transfers and roles can become part of the mechanisms for conducting analysis work thus supporting the visualization and communication of mental models and worldviews.

A transformation of the framework to an organizational method used to assist teams in problem solving can be viewed as a sense making process. The end result of this sense making process is an enhanced basis for decision-making, not a canned solution. The objective is to structure uncertainty and to promote self-reflection and evaluation of individual and group processes. It also encourages innovation via the visualization of mental models, worldviews and other communication and explanatory tools selected when using the framework.

\section{Analysis A: Individual}

Another objective associated with the SST framework is to create an individual process for structuring a problem in order to enhance decision -making capabilities. This is illustrated in Figure 3. Each participating individual creates a personal "map" of resources and competencies, as well as, identifies possibilities and the feasibility of achieving them. Since this is an "intra-individual" study, the word "I" is used within the framework.
"Situation": Where am I? What do I know about my own competence in this situation? What is my personal context at this moment? What tools, options, and resources do I have available to assist me in this situation? What are the possible solutions and are they feasible? The individual's experience is included in this analysis in addition to his or her physical skills and knowledge. Dynamics: What might the current activities be? What might be happening now? Why might I believe that? Might I be happy with these beliefs?

"Target": What do I see as the ultimate aim for my work in this situation? Where is the horizon for accomplishing my goals? Dynamics: What might I be willing or able to do? What assumptions might I be making?

(iii) "Vehicle": Is there any reason to why I am where I am? Am I in a situation where I am expected to contribute to something? If yes, why? What is possible given the current situation? What do I need that I don't have to achieve my objectives (e.g. what do I miss)? The individual's experience is included in this analysis in addition to his or her physical skills and knowledge. Dynamics: What might I be going to use or /what might I need to achieve this objective? Why might that be correct?

\begin{tabular}{|c|c|}
\hline (i). "Situation" & (ii). "Target" \\
"Why am I here?" & "Where do I want to go?" \\
"What do I know?" & "What does this mean?" \\
Issues: (information, experience, re- \\
sources, knowledge) & "What do I want?" \\
\hline $\begin{array}{c}\text { (iii). "Vehicle" } \\
\text { "What can I get?" } \\
\text { "What do I need?" } \\
\text { Issues: (possibilities, resources, } \\
\text { competencies) }\end{array}$ & "How do I get there?" "Road" \\
\end{tabular}

Figure 3: Analysis A. 
(iv) "Road": How does the road look? How shall I set the strategy to be able to use my competence and the available resources? (Note: This is also a valid discussion about my possibilities to cooperate with other people.) How shall I bring it all together into a meaningful strategy so I can create a road leading forward for myself as an interventee? I try to create and adapt a method to the context, which is demanded by the problem situation. I create a strategy for my use in terms of feasible methods and based on the problem description. Dynamics: What changes might I need to make? Why would these changes be trustworthy by the group or organization?

\section{Analysis B: Group - Individual Span}

A group of individuals (and their expressed worldviews), referred to as common grouping, is intended to be a support mechanism for understanding the problem statement and promoting communication among individuals. The use of groups is not intended to promote the dictatorial belief in a consensus. In a group setting, brainstorming and other tools help to uncover various solutions, some of which may seem extreme. These solutions are all considered viable in order to promote innovation in the group setting. Notice that the focus has shifted from intra-individual to inter-individual whereby the organizational actors work together to achieve a common goal. This is represented in Figure 4.

\begin{abstract}
"Grouping of worldviews": What differences between worldviews and mental constructs are there in the organization? What are the alternative and extreme views? What are the commonly held views? What are the main "mental constructs"? Differences among group members are kept in order to promote innovation. A synopsis of the various worldviews is noted thus limiting the number of alternatives without forcing a consensus. Dynamics: Why eliminate ideas before we actually believe that we are in a position to evaluate them? Why not keep several ideas even if they are viewed incompatible with each other?
\end{abstract}

"Maps of existing situations": Where are we today within the context of the organization? What do we know about the different individual understandings of the organizational situation? What are the different personal views of the organizational context at this moment? What tools, techniques, and resources are available to us? What are the possibilities? Personal experiences are included, not only physical resources. Dynamics: Why should the current assumptions of organizational resources, inclusive of individual experience and skill set, not be evaluated?

(iii) "Desired future situations": What do we think are the future situations in terms of organizational accomplishments? What would be the optimal future

\begin{tabular}{|c|c|}
\hline $\begin{array}{l}\text { (i). "Grouping of worldviews" } \\
\text { "What are our extreme views?" } \\
\text { "What are the common views?" } \\
\begin{array}{r}\text { Issues: (participants, stakeholders, "dif- } \\
\text { ferentiation of mental constructs") }\end{array}\end{array}$ & $\begin{array}{l}\text { (ii). "Map of existing situation" } \\
\text { "Where are we?" } \\
\text { "How do we understand our context?" }\end{array}$ \\
\hline $\begin{array}{l}\text { (iii). "Desired future situation" } \\
\text { "Where do we want to go?" } \\
\text { "What does this mean?" } \\
\text { "What do we want?" } \\
\text { Issues: (orientation, aim) }\end{array}$ & $\begin{array}{l}\text { (iv). "The alternative roads" } \\
\text { "How can we get there?" } \\
\text { "How shall we approach the situation?" }\end{array}$ \\
\hline
\end{tabular}

Figure 4: Analysis B. 
situations? Where do we want us to be in terms of personal achievements? What do we see as the ultimate aim for our work here? Where are the horizons? Dynamics: Why should the solution set of intended outcomes be seen as correct?

(iv)

\begin{abstract}
"The alternative roads": What are the alternative goals that could be pursued within the organization? How shall we determine what strategy to pursue to work towards our common goals? These questions are also valid for evaluating alternative solutions. What is politically feasible? What is possible to achieve with the existing resources in the existing culture and context? How shall we bring it all together to a meaningful strategy so that we can create a meaningful roadmap for goal accomplishment in our organization? Dynamics: Why should the assumptions of existing action strategies not be reevaluated?
\end{abstract}

\section{Evaluation (C) of Analysis Processes}

One major reason why evaluation of the results of both $A$ and $B$ activities is necessary is that when the analysis part of the framework is done, a question of feasibility arises. This evaluation process stems from the pursuit of quality in order to benefit the organization as a whole. In the SST framework, the evaluation is tied to reflections over the outcomes of analysis A and B. During this analysis process, it is important to note that differences in personal competencies, experiences, and contexts have a major impact on the understanding of shared experiences. This type of analysis is commonly found in qualitative research methods, which focuses on understanding multiple perspectives and the in depth understanding of unique individual and contextually dependent processes (Patton, 1987; Miles \& Huberman, 1994).

A systematic approach to an evaluation of the outcome of A and $\mathrm{B}$ activities can be viewed as a tool for utilizing the information that is made available in order to make effective organizational decisions. Such decision-making capabilities provide an impetus for organizational change in a positive manner. It is recognized, however, that evaluation also can be used as a tool for controlling activities. In such a perspective, the evaluation results become a viable basis for prioritization of chosen and evaluated activities. There is a close relationship between analysis and the evaluation of analysis activities. In practice, the difference between them is diffused.

The evaluation activity is not necessarily a straightforward process as there are personal influences that impact it. In the proposed SST framework, the evaluation activity is as a form of judgmental activity performed by the group. The objective of the evaluation process in this framework is to collect information about activities in order to achieve a judgmental base for a certain purpose. The purpose part of evaluation has a major influence on all evaluation activities. In this respect, it is important to have an understanding by all participants as to what this purpose is (e.g., what are the commonly defined goals being pursued by the group).

Evaluations can be seen as a normative activity and the only thing that they have in common with other evaluations is contextual dependence. This means that all evaluations are dependent on the contextual issues that surround them and these issues may be constantly changing. Patton (1987) suggests an understanding of the contextual dependency is to be seen as cardinal to evaluations based upon qualitative methods.

Questions and issues that might be of interest as part of the evaluation process associated with the SST framework include:

Constructive "what if?". What if my understanding is completely wrong? What if there are several "correct" understandings of reality even if they are incompatible with each other?

Positive (and constructive) criticisms. Descriptions, analysis might have underestimated the real benefits, values, and possibilities. What might have been forgotten? What about group dynamics aspects? Are there organizational issues, contexts, and other factors that might have had an impact?

(iii) Negative (and constructive) criticisms. Descriptions and analysis data might have missed relevant information, which could have identified more problematic issues. What possible issues might have been overlooked? What about risk analysis?

(iv) Competence. What about the limitations of personal knowledge? How are personal views, biases, and perspectives limiting the analysis process? (e.g., I can only see what I recognise.)

Not perfect. Even if the analysis process was of high quality, errors may have been introduced. Since this most probably is the case, critical evaluation becomes a necessary activity to search for errors, misperceptions, or other factors that will negatively impact the outcome of the analysis process.

Typically, the objective of the evaluation process is to provide a control structure for ongoing improvements of analysis activities. This means, for example, that there is a plan and a 
structure for certain processes that need to be followed. In this sense, evaluations may be used in several different ways including (but not limited to) a more traditional approach of questioning and correcting development plans.

According to Patton (1987), the challenge in evaluation is not only to uncover relevant information but also to get people to actually use it. That is to say that evaluation practices do not automatically result in learning activities and correction of less than perfect planning. An outcome of the evaluation process should be gained knowledge about the impact of individual and group decisions regarding development activities and other decisions that were made. The overall objective of the evaluation process in the SST framework is to re-evaluate and expand a knowledgebase for continuous learning.

In a cultural and sociological perspective, all evaluations can be analyzed as having political purposes. This is not always presented or even accepted to be transparent. In IS research, Walsham (1993) has commented on similar political behavior related to IT implementation. An example of organizational politics is when evaluations are used to make people responsible for some specific actions (e.g. "scapegoating"). At the same time, evaluation can be used to avoid being held responsible for the same actions, depending on how the evaluation is made, interpreted and acted upon. The purpose of evaluation, as proposed in this paper, has to do with aspect blindness. What this means is that the tendency can be described as the problem with finding what you look for, and not much more.

The orientation on usefulness of an evaluation has to do with trials or values of certain activities and their dependencies with regard to both the existing and future context. In any case, evaluations are to be looked upon as strategic activities. These strategic activities may be viewed as organizational change agents.

Evaluation as part of the SST framework can describe the meaningfulness, efficiency and ability to change in a certain activity context. Although evaluation of effects according to previously assumed realities might be the most actually used, there should certainly be a focus on the need to re-evaluate the many diversified versions of the sense making process itself. There is no such thing as a neutral or objective evaluation.

\section{Steps Forward}

There has been much talk about the "Information Society" creating social changes, and putting strain on both the modernistic competitive strategies and traditional business strategies (Rogers, 1986). At the same time, the attempts to implement these ideas in practice have either been relatively invisible or oversimplified. Weick (1995) points this out in his discussion about sense making in organizations whereby there is a large gap between ideas of interpretation and construction.

The strategies people seem to fall back upon, when dealing with these inconsistencies, are well explained by Weick (1995) in his sense making theoretical framework. These sense making activities can be described as being based upon organizing processes where communication and learning are central issues. The SST framework as presented here, can be seen as an example of a quest for the expansion of existing sense making processes in organizations. However, all sense making processes are intimately intertwined with their context and environment (Weick, 1995).

It is important to reiterate that the SST framework promotes contextually dependent adaptability. SST is meant to support a creation of a systems thinking process; that is, a form of contextual systems thinking process in action. This systems thinking part can be described concisely in the words of Senge (1990, p. 68):

Systems thinking is a discipline for seeing wholes. It is a framework for seeing interrelationships rather than things, for seeing patterns of change rather than static "snapshots." he also adds (p. 69): And systems thinking is a sensibility - for the subtle interconnectedness that gives living systems their unique character. Today, systems thinking is needed more than ever because we are becoming overwhelmed by complexity.

Systems thinking, as described by Senge, is insufficient to support stronger relationships with contextual dependencies. One possibly complementary approach to expand this kind of systems thinking is the ANT (Actor-Network Theory) as suggested by Latour $(1987,1999)$. Although ANT does claim to create a bridge between micro (intra-individual) and macro (inter-individual) perspectives, it has a tendency to underestimate contextual complexities in both. An example of a major problem in ANT is that the metaphysical part of the individual sense making processes (involved in double loop learning), does not seem to be supported.

Making sense of one's own sense making processes could, therefore, be seen as being in need of elements of rational explanation such as those offered by traditional positivist theories. However interpretation and sense making activities as such would still, by necessity, be under siege from communicative distortions (conscious and unconscious variants of "misunderstanding"). Inter-individual and intra-individual understanding as a possibility, but not as a necessity, which could be built upon strong argumentation has been suggested by Habermas (1984). 
This possibility of undistorted communication is seemingly built upon a belief in a communicative rationality, which is not evaluated according to more traditional positivistic rational criteria. A belief in any intelligible communicative act is thus based upon assumptions of a reality or some kind of selfimposed belief of a "common" consensus as a necessity. This belief in a basic consensus differs from Habermas (1984) in that it is individual, temporal and ad hoc which, when there surfaces a belief that a "misunderstanding" exists, might be questioned and re-evaluated.

Such a re-evaluation is the enhanced basis for the communicative refinement and a strengthening of argumentational efforts as proposed by Habermas (1984). In this way, traditional (positivist) understanding of meaning is rejected since within the realms of contextually dependent sense making processes a discovery of meaning is an individual personal creation and re-creation process based on assumptions and values rather than an undeviated relation to some objective reality.

\section{Conclusion}

The SST framework, presented in this paper, is mainly concerned with providing support for active sense making processes from intra and inter-individual perspectives. The SST framework is quite flexible in that it supports the temporary construction of an analysis method, but doesn't require the use of a pre-selected one. The SST, when applied by individuals and groups provides a communication structure within a specific organizational context. The theory that personal understanding of a "reality" varies with context (epistemological contextualism) is related to contextual dependency. This kind of contextualism is the basis for taking clues from contextual sense making activities. As a result, a useful but temporary SST method is created where processes and dynamics, in specific organizational contexts, are not eliminated up front due to a conceptually questionable illustration of elements or attributes.

This work attempts to present the SST framework as a support mechanism for inter- and intra-individual activities. It does not seek a compromise between sociological reductionism and psychological reductionism, but rather pursues the possibility of eliminating these types of reductionism. (Note: Sociological reductionism can be viewed as an assumption that psychology could be reduced to sociology. Psychological reductionism, on the other hand, can be seen as trying to reduce sociology to psychology.) This paper avoids any definition of analysis that gives priority to either of these two reductionisms, nor does it seek to form a synergy between them. With this in mind, the focus of this work is on the possible spin-offs accruing from the combinations of strengths in both discourses. In other words, it is an attempt to use the focus of a multiple perspective on our human sociability and our individuality as a driving force in the efforts to contextually integrate the otherwise polarised learning perspectives.

\section{References}

Ahrne G. (1994). Social Organizations - interactions inside, outside and between organizations. London: Sage.

Alter S. (1996). Information Systems - a management perspective. 2nd ed. Menlo Park Cal.: Benjamin/Cummings Publishing Company.

Anon. (2000). Grasping the ERP nettle. Reed Business Information Limited. Accessed May 4, 2000 at http:// ComputerWeekly.com

Agre P. E., \& Shuler D. ed. (1997). Reinventing Technology, Rediscovering Community - critical explorations of computing as a social practice. London: Ablex Publishing Corp.

Argyris C., \& Schön D. A. (1978). Organizational Learning. Reading Mass: Addison Wesley.

Argyris C., \& Schön D. A. (1996). Organizational Learning II - Theory, Method and Practice. Reading Mass: Addison Wesley.

Argyris C (1990). Overcoming Organizational Defenses: Facilitating Organizational Learning. Englewood Cliffs, New Jersey: Prentice Hall.

Avison D. E., \& Fitzgerald G. (1988). Information Systems Development, methodologies, techniques and tools. London: Blackwell Scientific Publications.

Bateson G. (1972). Steps to an Ecology of Mind. New York: Ballantine.

Bednar P., \& Wang V. (1994). System Design in Practice. Empirical study, analysis and discussion of organizational issues for system design processes (in Swedish). Lund: Dept. of Information \& Computer Science, Lund University.

Bednar P. (1999). Informatics - a working chaos for individuals and organizations. The impact of the notion of IS for System Analysis and Development (in Swedish). Lund: Dept. of Informatics, Lund University.

Brunsson N., \& Olsen J. P. (1993). The Reforming Organization. London: Routledge.

Cash J. I., Eccles R. G., Nohria N., Nolan R. L. (1994). Building The Information-Age Organization: structure, control and information technologies. Third Edition. Boston: Irwin, Harward Business School,.

Checkland P. (1981). Systems Thinking, Systems Practice. Chichester: John Wiley \& Sons.

Checkland P., \& Holwell S. (1998). Information, Systems and Information Systems - making sense of the field. Chichester: John Wiley \& Sons. 


\section{Strategic Systemic Framework}

Checkland P., \& Scholes J. (1990): Soft Systems Methodology in Action. Chichester: John Wiley \& Sons.

Child J. (1984). Organization - a guide to problems and practice. Second Edition. London: Paul Chapman Publishing.

Clegg, C. et al. (1996). The performance of Information Technology and the role of human and organizational factors. Report to the Economic and Social Research Council, UK, Systems Concepts Ltd. Volume 2, Issue 3. Accessed April 14, 2000 at http://www.systemconcepts.com/stds/clegg.html

Daft R. L. (1998). Organization theory and design. 6th ed. Cincinnati, Ohio: South-Western College Publishing.

Eriksen S. (1998). Knowing and the art of IT management. Lund: Dept. of Informatics. Lund University.

Groth L. (1999). Future Organizational Design - The Scope for the ITbased Enterprise. Chichester: Wiley.

Habermas J. (1984). The Theory of Communicative Action. Boston: Beacon Press.

Handy C. (1994). The Empty Raincoat. London: Hutchinson.

Hastings C. (1996). The New Organization: Growing the culture of organizational networking. London: McGraw-Hill.

Jayaratna N. (1994). Understanding and Evaluating Methodologies NIMSAD: A Systemic Framework. Berkshire: McGraw-Hill.

Langefors B. (1966). Theoretical Analysis of Information Systems. Lund: Studentlitteratur.

Langefors B. (1995). Essays on Infology - Summing up and Planning for the Future. Lund: Studentlitteratur.

Latour B. (1987). Science in Action. Milton Keynes: Open University Press.
Latour B. (1999). Pandora's Hope, Essays on the reality of science studies. Cambridge, Mass: Harvard University Press.

Maturana H. R., \& Varela F. J. (1980). Autopoiesis and Cognition, The Realization of the Living. Dordrecht: Reidel Publishing Company.

Miles M. B., \& Huberman A. M. (1994). Qualitative Data Analysis. Thousand Oaks: Sage Publications.

Patton M. Q. (1987). How to Use Qualitative Methods in Evaluation. Newbury Park Cal: Sage Publications, Inc.

Robson W. (1997). Strategic Management \& Information Systems. 2nd ed. London: Pitman Publishing.

Rogers E., \& Agarwala-Rogers R. (1976). Communication in Organizations. New York: The Free Press.

Rogers E. M. (1986). Communication Technology, the new media in society. New York: The Free Press.

Senge P. M. (1990). The Fifth Discipline, The Art \& Practice of The Learning Organization. reprint 1999. London: Random House.

Sjöstrand S.-E. (1997). The Two Faces of Management: The Janus Factor. London: International Thomson Business Press.

Travica B. (1999). New Organizational Designs: Information Aspects. Stamford, CT: Ablex Publishing Corporation.

Walsham G. (1993). Interpreting information systems in organizations. Chichester: John Wiley \& Sons.

Weick K. (1995). Sense making in organizations. Thousand Oaks, Cal: Sage Publications.

Yourdon E. (1989). Modern Structured Analysis. Englewood Cliffs, NJ: Prentice-Hall.

Zack M. H. ed. (1999). Knowledge and Strategy. Woburn, MA: Butterworth-Heinemann. 